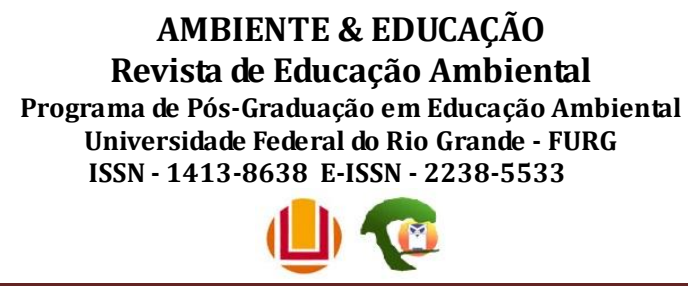

Vol. 22, n. 1, 2017.

\title{
TEATRALIZANDO A EDUCAÇÃO AMBIENTAL
}

\author{
Caroline Araujo de Oliveira ${ }^{1}$, Jacqueline Shirley Santos ${ }^{2}$, Fernando Paixão Rosa ${ }^{3}$, Viviane da Silva Brito ${ }^{4}$, \\ Talita Moura Fukuoka ${ }^{5}$, Vanessa Aparecida André da Silva ${ }^{6}$, Paulo Renato de Souza ${ }^{7}$, \\ Rodrigo de Oliveira Marcon ${ }^{8}$, Vanessa Aparecida Soares ${ }^{9}$, Debora Ayame Higuchi ${ }^{10}$
}

\begin{abstract}
RESUMO
A educação ambiental pode ser considerada por toda ação educativa que contribui para a formação de cidadãos conscientes da preservação do meio ambiente, aptos também a tomar decisões coletivas necessárias para o desenvolvimento de uma sociedade sustentável. Uma das formas de ter a ação de extensão é por meio de projetos com caráter educativo. O presente artigo considera que atividades lúdicas, em especial o teatro, possa contribuir para uma educação ambiental mais significativa, promovendo a prática e a reflexão crítica, com o intuito de desenvolver cidadãos capazes de conceber uma responsabilidade ambiental. Esta proposta une o ensino de ciências com a realização de experimentos químicos à expressão teatral na busca da valorização dos conceitos aprendidos. O teatro foi apresentado ao ensino fundamental II na rede pública e a validação da pesquisa foi realizada com aplicação de questionários pré e pós apresentação, abordando temas relacionados com a responsabilidade socioambiental. Os resultados coletados corroboram com outros autores, demonstrando que a prática do teatro é uma ferramenta educacional, favorecendo assimilação de conceitos e neste caso, auxiliando na conscientização ambiental.
\end{abstract}

Palavras-chave: Educação ambiental. Teatro. Ensino de Ciências.

\begin{abstract}
Environmental education can be understood with all educational action that contributes to the formation of citizens aware of the preservation of the environment and able to make collective decisions on environmental issues necessary for the development of a sustainable society. One of the ways of having the extension action is through projects with an educational character. The present article considers that ludic activities, especially theater, can contribute to a more meaningful environmental education, promoting practical and critical reflection, with the intention of developing citizens capable of conceiving an environmental responsibility. his proposal unites the teaching of sciences with the accomplishment of chemical experiments to the theatrical expression in the search of the valorization of the concepts learned. The theater was presented to elementary school II in the public network and the validation of the research was carried out with the application of pre and post presentation questionnaires, addressing themes related to social and environmental responsibility. The results collected corroborate with other authors, demonstrating that the practice of theater is an educational tool, favoring assimilation of concepts and in this case, it assists in environmental awareness.
\end{abstract}

Keywords: Environmental education. Theater. Science teaching.

1IFSP - campus Suzano.

2IFSP - campus Suzano.

3IFSP - campus Suzano.

4IFSP - campus Suzano.

5IFSP - campus Suzano.

6IFSP - campus Suzano.

7IFSP - campus Suzano.

8IFSP - campus Suzano.

9IFSP - campus Suzano

10 IFSP - campus Suzano. 


\section{INTRODUÇÃO}

A Terra sempre esteve em constantes transformações naturais ou advindas de ações antropológicas. Estas, porém, têm se acentuado nas últimas décadas, contribuindo para o desequilíbrio ecológico do planeta. É consenso que a implantação de ações que minimizem a participação do homem neste processo é necessária. De acordo com Passos e Nogueira (2009), a preocupação com o desenvolvimento sustentável teve seu marco histórico mundial com a Conferência de Estocolmo, em 1972, onde líderes mundiais se reuniram para discutir ações mais sustentáveis. Hoje o Brasil é considerado um dos países que possui uma das mais completas legislações ambientais do mundo, apresentando mais de dezessete leis, sendo destacado neste trabalho a Lei N9.795 de 1999 - Lei da Educação Ambiental - em seu Art. $1^{\circ}$ afirma:

Processo em que se busca despertar a preocupação individual e coletiva para a questão ambiental, garantindo o acesso à informação em linguagem adequada, contribuindo para o desenvolvimento de uma consciência crítica e estimulando o enfrentamento das questões ambientais e sociais.

E o artigo $2^{\circ}$ da Lei 9.795/99 que estabelece:

A educação ambiental é um componente essencial e permanente da educação nacional, devendo estar presente, de forma articulada, em todos os níveis e modalidades do processo educativo, em caráter formal e não-formal.

Apenas existir legislações que preveem a Educação Ambiental, não é o bastante, é preciso haver uma mudança no pensamento e ações no que diz respeito ao meio ambiente. A dimensão ambiental configura-se crescentemente como uma questão que envolve um conjunto de atores do universo educativo, potencializando o engajamento dos diversos sistemas de conhecimento, a capacitação de profissionais e a comunidade universitária numa perspectiva interdisciplinar (JACOBI, 2003).

É possível entender que, embora a educação das pessoas esteja associada à experiência que o indivíduo adquire no espaço escolar (educação formal), é importante considerarmos a existência de um processo educativo não-formal. Desta maneira, partiu-se da ideia de que a ciência, por sua própria natureza, tem de ser aberta, comunicada não apenas à comunidade científica, sobretudo de forma diferente na sociedade em geral, a começar pela escola (SILVEIRA, et al., 2009).

Pode ser observado nos últimos anos um crescente número de relatos de experiências em educar para a responsabilidade socioambiental, como por exemplo, o trabalho da ONG SOS Mata-Atlântica, que utiliza o monitoramento da qualidade das águas no Brasil, por comunidades, estimulando também a gestão participativa dos recursos 


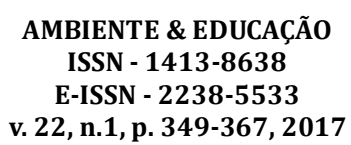

hídricos. Outro exemplo é o trabalho de Fetter; Mulher; Silva (2006), onde relata sua experiência desenvolvendo hortas escolares. Considerando a tecnologia da informação, é possível encontrar, vários jogos eletrônicos, disponíveis gratuitamente, que usam como temática reciclagem, contaminação do solo, ar e rios, entre outros.

Segundo autores, como Cunha e Silva (2012), Fortuna (2000), o uso de ferramentas lúdicas nas escolas é capaz de aumentar o interesse pelo aprendizado. Oliveira (1985, p.74) em seu trabalho, escreve:

O lúdico é um recurso metodológico capaz de propiciar uma aprendizagem espontânea e natural. Estimula a crítica, a criatividade, a sociabilização, sendo, portanto, conhecido como uma das atividades mais significativas - senão a mais significativa - pelo seu conteúdo pedagógico social.

Uma das iniciativas da aplicação do lúdico nas escolas é na forma de teatro, Santos (2016) utilizou o teatro como ferramenta da educação ambiental.

A área da química, ainda pode contar com um complemento muito interessante em peças de teatro, que é a experimentação. Segundo Giordan (1999) é consenso que a experimentação química desperta interesse entre os alunos, independentemente do nível de escolarização. Quando os experimentos demonstrativos são contextualizados na temática ambiental, podem ilustrar problemas ambientais, de forma que assimilação do que se pretende ensinar seja mais ilustrativa, atrativa e eficaz.

Este artigo teve como proposta utilizar experimentos químicos contextualizados na problemática ambiental atual, apresentados na forma de uma peça teatral, levando às escolas públicas do município de Suzano-SP, ilustrando as consequências da ação do homem nos fenômenos da natureza e a importância da preservação do meio ambiente por todos.

\section{METODOLOGIA}

A peça teatral foi criada pelos autores do trabalho em 2014 e no mesmo ano apresentada a aproximadamente duzentos alunos da rede de ensino básico de educação do Ensino Fundamental II, contou com a participação de cinco alunos do curso superior em Tecnologia de Processos Químicos do Instituto Federal de São Paulo, câmpus Suzano. Esses alunos foram responsáveis pela execução da peça, criação do cenário, figurino, escolhas das imagens e músicas, supervisionados pelos professores envolvidos no projeto. 


\section{$O$ contexto da peça}

Toda a exposição teatral foi produzida de forma a induzir a plateia a refletir sobre sua responsabilidade para com o meio ambiente, bem como sua preservação.

A história se passa no ano de 2085 e mostra a dura vida de um senhor que, assim como o resto da humanidade, sofre com as condições ambientais em completo desequilíbrio. Em uma tarde, após banhar-se com lenços umedecidos pela escassez de água, o senhor adormece e, em seu sonho, regressa ao ano de 2014, onde encontra antigos amigos que debatem sobre alternativas para preservar o meio ambiente e mudar o futuro.

\section{Avaliação do caráter educativo da peça teatral realizada}

Para fins de avaliação foram elaborados questionários (figuras 1 e 2) para serem respondidos voluntariamente pelos expectadores pré e pós apresentação da peça teatral, figuras 1 e 2 respectivamente.

*De acordo com as afirmações abaixo faça um $X$ no rosto que melhor expressa a sua opinião: 1) Eu sou o responsável por cuidar do meio ambiente.

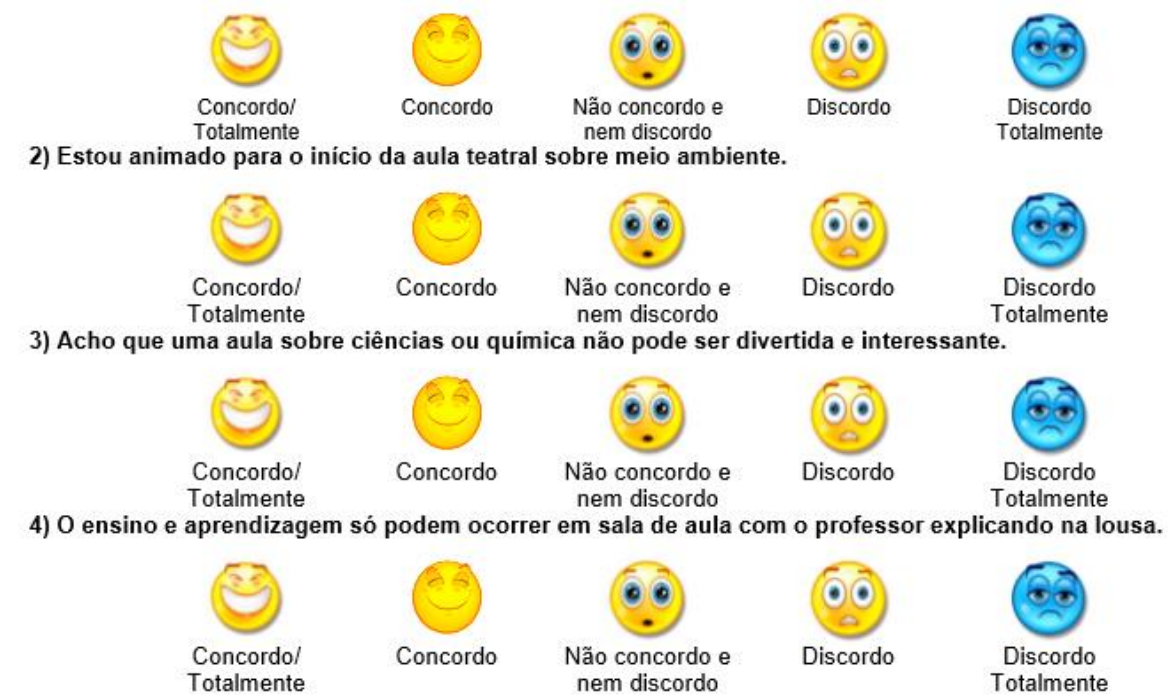

Figura 1: Questionário pré apresentação. 
*De acordo com as afirmações abaixo faça um $X$ no rosto que melhor expressa a sua opinião: 1) A aula foi bem divertida e superou minhas expectativas.

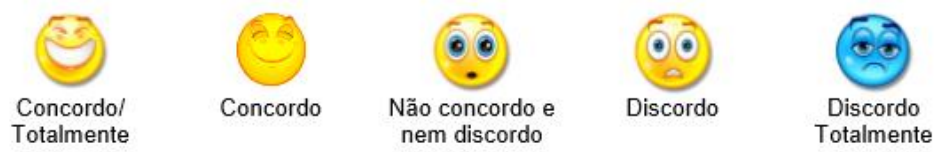

2) Com a apresentação pude aprender sobre vários assuntos ligados ao Meio Ambiente.

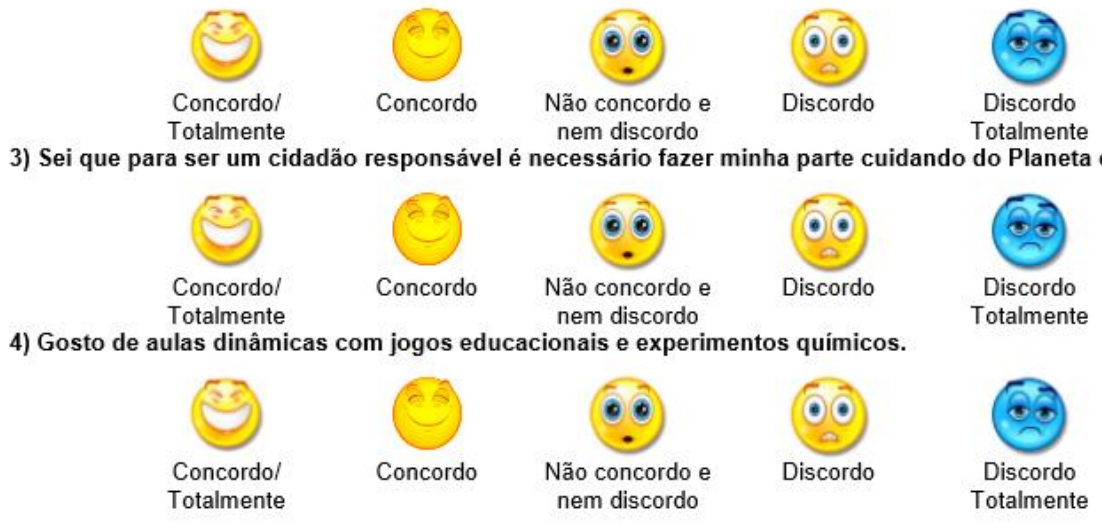

Figura 2: Questionário pós apresentação.

\section{Material audiovisual}

Para elaboração da parte audiovisual do teatro, os vídeos exibidos traziam informações importantes sobre poluição do ar, a problemática do lixo e reciclagem. Esses vídeos, além de ser uma forma de enriquecer o projeto, também serviam como mudança de cenas, possibilitando tempo para a organização dos experimentos da próxima cena. Parte desses vídeos foram retirados do site www.youtube.com.br, porém alguns foram elaborados especialmente para as apresentações.

\section{Experimentos realizados}

Os experimentos foram baseados no trabalho de Arroio e colaboradores (2006), que motiva o interesse científico apresentando de forma lúdica experimentos químicos.

\section{Varinha mágica}

Objetivo: Simular queimadas, a fim de demonstrar as consequências para a humanidade.

Materiais e Reagentes: 
Chumaço de algodão, conta-gotas, bastão de vidro ("varinha mágica" para este experimento), vidro de relógio, cadinho, álcool, permanganato de potássio $\left(\mathrm{KMnO}_{4}\right)$, ácido sulfúrico concentrado $\left(\mathrm{H}_{2} \mathrm{SO}_{4}\right)$.

\section{Método}

Colocou-se o chumaço de algodão no cadinho, juntamente com gotas de álcool etílico até ele ficar úmido. Em seguida, adicionou-se alguns cristais de permanganato de potássio $\left(\mathrm{KMnO}_{4}\right)$ no vidro de relógio e com auxílio de um conta-gotas pingou-se algumas gotas de ácido sulfúrico concentrado. Misturou-se o permanganato de potássio $\left(\mathrm{KMnO}_{4}\right)$ e o ácido sulfúrico concentrado $\left(\mathrm{H}_{2} \mathrm{SO}_{4}\right)$ com um bastão de vidro, certificando-se de que na ponta do bastão de vidro ficasse contida a mistura das duas substâncias. Por último, encostou-se o bastão de vidro com a mistura no algodão umedecido com álcool. O algodão entrou em combustão.

\section{Chuva ácida}

Objetivo: Demonstrar o que é, como ocorre e suas consequências para o meio ambiente.

\section{Materiais e Reagentes:}

Enxofre (S), pote de vidro com tampa, fósforo, fio de cobre, indicador de $\mathrm{pH}$ azul de bromotimol $\left(\mathrm{C}_{27} \mathrm{H}_{28} \mathrm{Br}_{2} \mathrm{O}_{5} \mathrm{~S}\right)$ e água.

\section{Método}

Primeiramente, enrolou-se o fio de cobre, de forma que este formasse uma pequena espécie de recipiente. Com este recipiente, pegou-se uma quantidade de enxofre e esquentou-se com um fósforo até este entrar em combustão e imediatamente acoplou-se esse fio no pote de vidro, já contendo água com algumas gotas de azul de bromotimol, tornando essa água azulada. Tampou-se o pote e observou-se a mudança de coloração da água azulada para amarelo, indicando assim a mudança de $\mathrm{pH}$.

\section{Pasta de dente de elefante}

Objetivo: Demonstrar de forma divertida uma tentativa de preservação do meio ambiente produzindo seus próprios produtos, a fim de diminuir o lixo e o consumo desnecessário. 
Materiais e Reagentes:

Água oxigenada concentrada $\left(\mathrm{H}_{2} \mathrm{O}_{2}\right)$, sabão ou detergente, iodeto de potássio (KI) e uma proveta de $50 \mathrm{~mL}$.

\section{Métodos}

Dentro da proveta, colocou-se $10 \mathrm{~mL}$ de detergente e $20 \mathrm{~mL}$ de água oxigenada. Em seguida, com cuidado, adicionou-se cerca de $2 \mathrm{~g}$ de iodeto de potássio à mistura dentro da proveta. Imediatamente, foi possível observar a formação de uma grande quantidade de espuma.

\section{Gelando a latinha em 3 minutos}

Objetivo: Demonstrar de forma divertida uma tentativa de preservação do meio ambiente, reduzindo o consumo de energia elétrica.

Materiais e Reagentes:

Gelo, álcool, sal de cozinha, caixa térmica e lata de refrigerante.

\section{Métodos}

Na caixa térmica, acrescentou-se uma quantidade de gelo, álcool e sal, suficiente para manter a lata de refrigerante submersa. Aguardou-se três minutos e verificou-se a mudança de temperatura da lata.

\section{Água furiosa}

Objetivo: Por meio de brincadeiras e analogias, informar sobre a poluição da água.

Materiais e reagentes:

Um balão volumétrico de $500 \mathrm{~mL}$, dois béqueres de $100 \mathrm{~mL}$, hidróxido de sódio $(\mathrm{NaOH})$, azul de metileno $\left(\mathrm{C}_{16} \mathrm{H}_{18} \mathrm{~N}_{3} \mathrm{SCl}\right)$, glicose $\left(\mathrm{C}_{6} \mathrm{H}_{12} \mathrm{O}_{6}\right)$ e água.

\section{Métodos}

Em um béquer de $100 \mathrm{~mL}$, misturou-se $100 \mathrm{ml}$ de água a 3,5g de hidróxido de sódio. No segundo béquer de $100 \mathrm{~mL}$, misturou-se $100 \mathrm{ml}$ de água a $6 \mathrm{~g}$ de glicose. Após a dissolução de ambas as substâncias, misturou-as no balão volumétrico, acrescentado algumas gotas de azul de metileno. 
ISSN- 1413-8638

E-ISSN - 2238-5533

v. 22 , n. 1, p. 349-367, 2017

\section{Destruição da camada de ozônio}

Objetivo: Fazer uma analogia, demonstrando como os aerossóis podem destruir a camada de ozônio e apresentar os riscos que podem trazer a saúde e ao meio ambiente.

Materiais:

Globo terrestre confeccionado de isopor, placa de isopor, thinner e recipiente spray.

\section{Métodos}

Colocou-se o thinner em um recipiente spray. Anexou-se um pedaço da placa de isopor na superfície do globo e por último, espirrou-se algumas gotas de thinner nesta placa.

\section{Água que muda de cor}

Objetivo: Demonstrar como a poluição dos rios alteram o $\mathrm{pH}$ da água que consumimos.

Materiais e reagentes:

Água, fenolftaleína $\left(\mathrm{C}_{20} \mathrm{H}_{16} \mathrm{O}_{4}\right)$, hidróxido de sódio $(\mathrm{NaOH})$ e três béqueres de $50 \mathrm{~mL}$.

\section{Métodos}

Em dois béqueres foram adicionados uma mistura de água e o hidróxido de sódio. No terceiro béquer foi adicionado apenas água. Foram pingadas algumas gotas de fenolftaleína nos três, observando em que havia mudança de coloração apenas nos béqueres com hidróxido de sódio, assim indicando o quão básico aquela substância estava.

\section{DESENVOLVIMENTO DAS CENAS}

Com o objetivo de primeiramente sensibilizar o espectador de um futuro desastroso que pode influenciar no cotidiano de qualquer cidadão foi construída a seguinte sinopse:

\section{Cena 1}

Ocorre no futuro no ano de 2085.

O senhor Fernando chega tossindo e reclamando das condições atuais do planeta:

"Faz tempo que eu não consigo respirar direito. E esse calor? Está ainda pior com a racionalização de água! ” 
Ele liga a televisão, que está passando o noticiário, com as seguintes notícias urgentes:

- O rio mais importante do país morre (Rio Amazonas).

- Mais uma lei aprovada: pessoas só devem sair de casa utilizando máscaras de oxigênio.

- Maior frente fria dos últimos anos, marcando $30^{\circ} \mathrm{C}$.

- Desaparecimento de cidades litorâneas, devido ao derretimento das geleiras.

Soa a voz do inconsciente: "E você? O que poderia ter feito para evitar tudo isso?"

As demais cenas serviram para abordar os temas ambientais: poluição do ar, poluição do solo e da água e mostrar como eles estão presentes na vida diária da sociedade e as ações que podem proporcionar melhor qualidade de vida aos cidadãos.

Cena 2 - Poluição do Ar

O Senhor, pensativo, adormece e sonha. Em seu sonho ele volta ao ano de 2014, quando tinha 14 anos, na rua de sua antiga casa. Lá ele avista duas amigas de infância, Carol e Vanessa, que correm ao seu encontro, porém são interrompidas por um caminhão que passa entre eles soltando fumaça. Todos tossem.

Uma das amigas diz que sabe ilustrar as causas e as consequências das queimadas e a queima de combustíveis fósseis:

"Pessoal, vocês sabiam que a fumaça, não só desse caminhão, mas de todos os veículos desregulados e empresas ajudam a destruir a camada de ozônio e causam um fenômeno chamado chuva ácida? Olha só vou mostrar para vocês o que é a chuva ácida, usando minha varinha mágica!"

Neste momento realizou-se primeiramente o experimento varinha mágica, 2.4.2, no qual se utilizou uma pequena maquete (figura 3) simulando um bairro, com algumas árvores pegando fogo e empresas e carros soltando fumaça e em seguida explicou-se as consequências da poluição e formação da chuva ácida, experimento 2.4.2. 


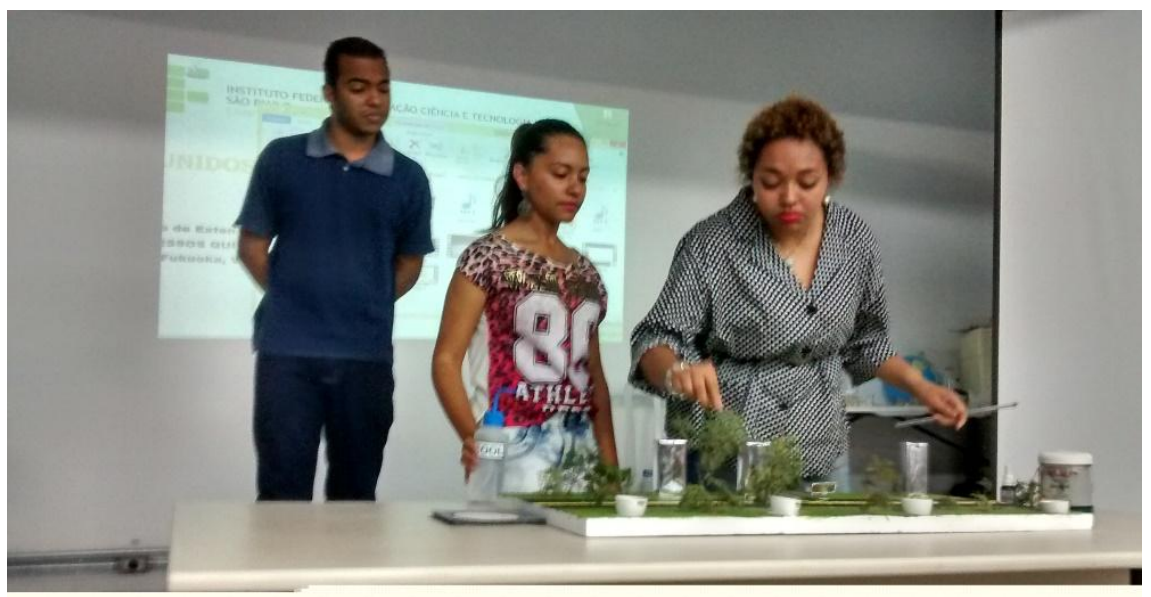

Figura 3: Maquete sobre poluição do ar.

Após a realização desses experimentos é explicado:

“A chuva ácida é um dos problemas ambientes mais presentes nas grandes cidades. Ela é causada pelos gases tóxicos, como, o dióxido de enxofre e óxidos de nitrogênio, liberados na queima de combustíveis como o carvão e o petróleo. Depois que as chaminés das indústrias e os escapamentos dos carros despejam no ar a sujeira da combustão, uma parte da poluição reage com o vapor d'água e outros componentes da atmosfera. Nesse processo, os gases poluentes se transformam em ácidos, que caem sobre a terra misturados com as gotas de tempestade, neblina ou nevoeiro. Daí vem a acidez da chuva, que pode destruir florestas, acabar com os nutrientes do solo, matar a vida aquática e prejudicar a saúde humana."

Fernando, admirado com os efeitos da chuva ácida, começa a questionar sobre a poluição do ar:

"Então é verdade que esses gases poluentes, também causam a destruição da camada de estufa?" As amigas perguntam espantadas:

"CAMADA DE ESTUFA? O que é isso?"

Uma delas percebe o equívoco do garoto e corrige:

"Você não quis dizer CAMADA DE OZÔNIO e EFEITO ESTUFA?"

"Tanto faz, não é tudo a mesma coisa?"

"Eu acho que não."

A amiga de Fernando questiona a plateia, para saber quantos pensam que os dois são a mesma coisa.

Uma terceira colega entra na cena carregando um globo terrestre e explica a definição do Efeito Estufa e a importância da preservação da camada de ozônio 


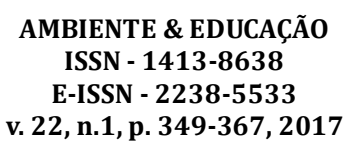

"São dois fenômenos diferentes: o efeito estufa, é um fenômeno natural que mantém o planeta aquecido. Ele funciona da seguinte maneira: O calor do sol entra na Terra e certos gases chamados gases estufas seguram esse calor aqui, evitando que ele seja liberado para o espaço. Esses gases são principalmente, o dióxido de carbono $\left(\mathrm{CO}_{2}\right)$, óxido nitroso $\left(\mathrm{N}_{2} \mathrm{O}\right)$, metano $\left(\mathrm{CH}_{4}\right)$, clorofluorcarbonetos (CFCs) e hidrofluorcarbonetos (HFCs). Porém nos últimos anos a quantidade desses gases têm aumentado, prendendo mais calor do que o necessário na terra.

A camada de ozônio é formada por três átomos de oxigênio, que envolve a Terra e a protege contra os raios ultravioletas vindos do Sol. Esses raios são perigosos, pois danificam nossa pele, e até mesmo nosso DNA, podendo causar câncer de pele e problemas nas córneas. A destruição dessa camada, por sua vez, é resultado principalmente da emissão dos gases CFCs. CFCs são emitidos na atmosfera através de sprays, ar condicionados e equipamentos industriais, ou até alguns anos atrás, liberados ao abrirmos a porta de nossas geladeiras! Esses gases, destroem a camada de ozônio. Vou demonstrar! ". Neste momento executa-se a experiência destruição da camada de ozônio, experimento 2.4.3. (figura 4).

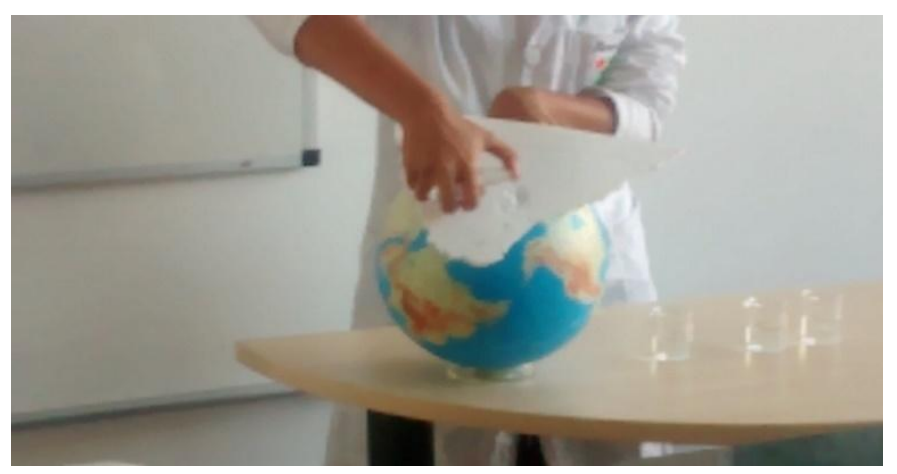

Figura 4: Simulação da destruição da camada de ozônio.

Cena 3 - Poluição do Solo e da Água

Fernando entra em cena brincando com bolhas de sabão e duas colegas a frente conversam sobre o que aprenderam na última aula de ciências, referente a poluição dos rios: "Muito legal aquele conteúdo de Química ambiental que tivemos na aula passada, não?" Fernando neste momento para de brincar e, pergunta:

"Que aula? Eu faltei na última sexta-feira." Ele responde: 
"Ninguém mandou você faltar! - Mas relutante acaba explicando - "Sobre poluição da água. E se eu fosse você, não ficaria brincando com detergente até ter certeza da sua origem!"

\section{"Como assim?"}

"Pois é, a professora falou que existe dois tipos de detergentes: os não-degradáveis e os biodegradáveis. Os não-biodegradáveis, causam nos rios um fenômeno chamado: Cisnes de detergente, que são aquelas espumas esbranquiçadas nas beiradas dos rios. Esse acúmulo de detergente nos rios, impede a entrada de oxigênio, tornando a água imprópria para o uso."

Nesse momento, entra uma terceira pessoa trazendo vários copos (aparentemente) com água e também uma atividade que diz ter sido feita em sala de aula e que simula os lençóis freáticos:

"Aqui! Eu trouxe pra você ver a atividade de sexta. Esse pote representa o perfil de nosso solo, assim podemos demonstrar como são formados os lençóis freáticos e como a poluição dos solos podem afetar nossa água. Veja (figura 5)!"

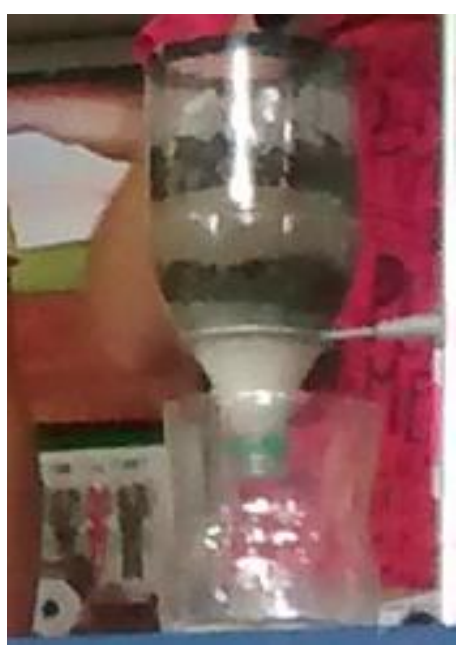

Figura 5: Maquete da formação dos lençóis freáticos.

"A partir dessa água filtrada naturalmente, temos as formações dos lençóis freáticos, importante para o planeta. Quando contaminamos o solo, seja com agrotóxicos ou mesmo lixo, os nutrientes da terra se perdem, portando quando água passa por ela, também é contaminada. " A outra amiga questiona:

"Então nem sempre a água que bebemos está realmente limpa?"

"Se ela teve o tratamento adequado, podemos beber tranquilamente, mas eu trouxe alguns copos com água para serem examinados. Vamos fazer um teste? Eu tenho uma 


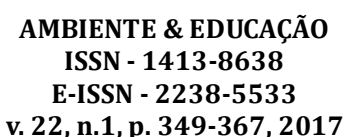

substância que indica se a água é potável ou não. Que tal pedir ajuda dos nossos amigos para isso?

Três expectadores são convidados a participarem desta cena. É solicitado que eles analisem o cheiro e a cor da água para dizer se a água é potável ou não. Neste momento foi apresentada a Experiência água que muda de cor, 2.4.7 e água furiosa, 2.4.5 e apresentada uma breve explicação sobre $\mathrm{pH}$ da água.

\section{Cena 4 - Reaproveitamento}

Um dos amigos entra em cena de jaleco, óculos de proteção e luva, com diversas vidrarias e reagentes, e começa a misturá-los. Os demais amigos entram em cena, espantados, perguntam ao demais o que ele está fazendo, que responde:

"Estou criando meus próprios produtos!"

"Mas, por quê?"

"Ué? Vocês não sabem? O consumismo desnecessário está ajudando a destruir o planeta também! Pois a cada dia a produção de lixo aumenta, só na cidade de São Paulo, por exemplo, cada pessoa, em média produz diariamente $1 \mathrm{~kg}$ de lixo, por dia são geradas 15.000 toneladas de lixo no total. "Nossa, quanto lixo! E, é verdade que o lixo que produzimos, contribui para termos enchentes, pois entope nossos bueiros e nos traz diversas doenças?"

"É sim! Mas não só isso, o lixo também produz metano, que ajuda no aumento do efeito estufa e chorume, que polui o solo e a água, por isso decidi produzir minhas próprias coisas! Assim produzo menos lixo!”

"O que você está tentando produzir?"

"Minha própria pasta de dente!"

"Nossa, mas, não é muito difícil? Precisa estudar muito para produzir pasta de dente."

"Que nada encontrei uma receita muito fácil na internet, presta atenção!" Neste momento a Experiência, 2.4 .3, pasta de dente de elefante é apresentada.

Os amigos assustados comentam:

"Meu Deus! Não para de crescer, o que você fez? Acho que não deu certo!"

"É verdade, e agora?"

Nesse momento, entra o terceiro amigo com outra mesa onde se encontra um copo com água e diz: 
“Essa sua pasta de dente não está com nada, eu sei um jeito muito melhor de ajudar o planeta!

Produzindo meu próprio gelo, e diminuindo o consumo de energia elétrica!"

"Duvido! Como você vai fazer isso? É impossível! "

"Não é não, esqueceu que eu tenho uma varinha mágica? Olha só:

Apresentação da Experiência, 2.4.4, gelo instantâneo.

$\mathrm{O}$ amiguinho que não tentou nenhuma ideia mirabolante para ajudar o planeta diz:

"E quem não tem uma varinha mágica, como faz? Vocês são muito bobos, existem formas bem mais fáceis de ajudar nosso planeta, vou contar para vocês: existe uma coisa chamada reciclagem, na qual alguns tipos de materiais podem ser transformados em outros, além disso não precisamos de mágica para diminuir o consumo de energia e o de água! Podemos simplesmente economizar, seja tomando banhos mais rápidos, fechando a torneira enquanto escovamos os dentes, não lavar o quintal e a calçada com a mangueira, ou mesmo desligando as luzes ao sairmos de casa!" "Poxa é verdade, você tem razão! Mas, me fala mais um pouquinho sobre essa tal de reciclagem! " "Tá bom venham comigo, vou mostrar para vocês. "Todos saem de cena e passa a ser exibido um vídeo sobre o lixo.

Cena 5 - Os 3R's

Todos voltam, trazendo a máquina da reciclagem, e explicam como funciona:

"Está vendo essas lixeiras coloridas? Cada uma delas serve para ser depositado um material diferente, a azul papel, a vermelha plástico, a amarela metal e a verde vidro. Esse lixo é recolhido e levado para postos de reciclagem, nos quais são transformados em novos objetos!"

"Que legal! Isso me fez lembrar uma coisa que minha mãe me contou. Existem três erres mágicos, que nos ajudam a salvar o planeta, eles são Reduzir, Reutilizar e Reciclar! ”

"Supimpa! Conta mais..."

"Espera aí, vamos colocar a máquina para funcionar e ela nos contará mais sobre isso, pois ela só funciona ao escutar uma música! " (Neste momento é apresentado o vídeo musical dos 3R's do Jack Johnson).

- Enquanto isso diversos lixos são colocados na máquina (Figura 6) e são transformados em objetos novos. 


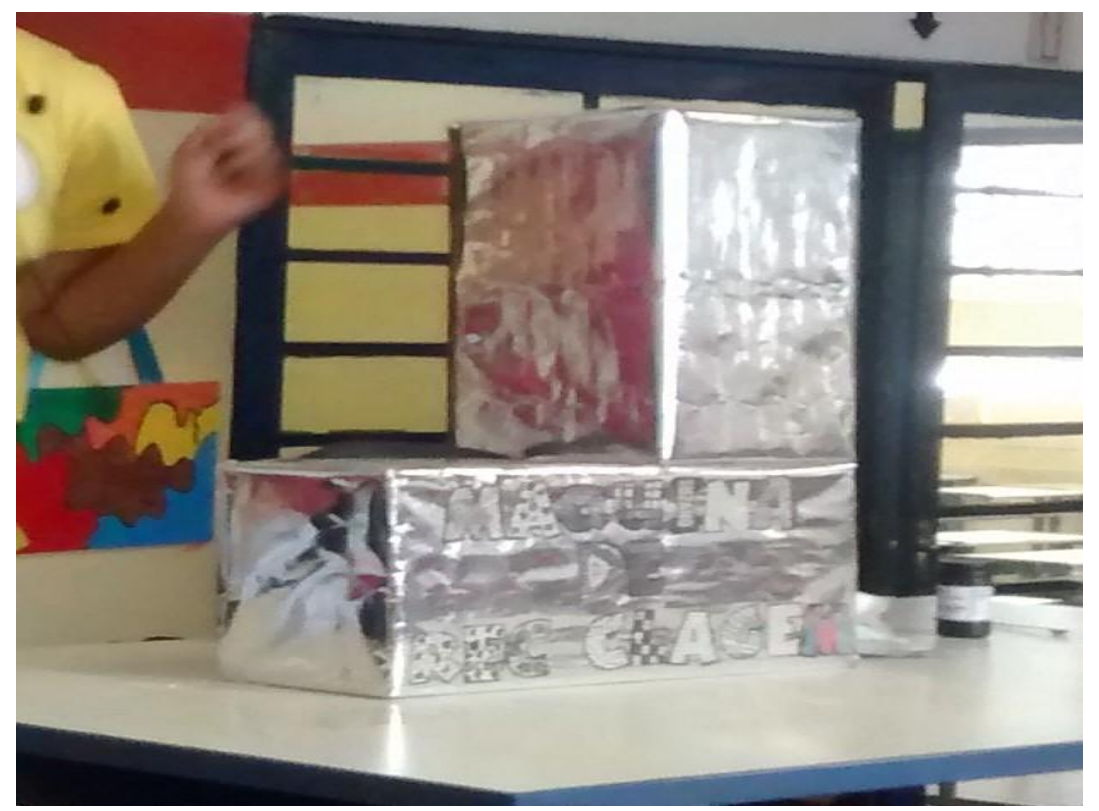

Figura 6: Máquina da Reciclagem.

Ao acabar o vídeo, temos a explicação:

"Portanto para utilizar os três erres na sua vida, você pode:

Reutilizar materiais:

- Circular materiais que possam servir para outras pessoas (roupas, móveis, aparelhos domésticos, livros, brinquedos...);

- Utilizar embalagens retornáveis;

- Apoiar as atividades de recuperação e conservação dos objetos.

Reduzir:

- Exigir produtos mais duráveis;

- Adotar um consumo mais racional;

- Repartir com outras pessoas o uso de materiais (equipamentos, jornais, livros...).

Reciclar:

- Participar da coleta seletiva para que seja enviado o material reciclável para as indústrias de reprocessamento os materiais que possam ser reciclados. Um dos alunos em cena, diz: "Nossa foi ótimo reencontrar vocês, aprendemos muito! A partir de hoje, vou colocar em prática as ações sustentáveis. Mas, já é muito tarde, tenho que voltar para casa! Tchau".

"Eu também adorei, mas tenho que ir. Tchau!"

As amigas voltam e falam:

"Não se esqueça, o único que pode salvar o planeta é você!"

Fernando encontra-se sozinho, neste momento: 
- Passa um vídeo sobre viagem no tempo.

Fernando acorda, encontra sua netinha e percebe que está no ano de 2085:

"Vô, vô, vamos passear?"

"Sim vamos! Sabe, se nós tivéssemos nos preocupado mais com nosso planeta, hoje teríamos uma vida diferente. Eu queria tanto voltar no tempo e mudar minhas atitudes, levar uma vida com:

\section{SUSTENTABILIDADE! ”}

"Mas vô, o que é sustentabilidade?"

É passado um vídeo, neste momento, explicando o que é sustentabilidade

- Vídeo sobre sustentabilidade:

A neta do senhor Fernando, diz:

"Mas vô, se isso é sustentabilidade, não podemos tentar por em prática ainda?

"Você tem razão. Nunca é tarde para mudarmos o mundo!

Todos saem de cena e encerra a apresentação!

\section{RESULTADOS E DISCUSSÕES}

Impressões da equipe executora:

A cena 1 sensibilizou de forma divertida a plateia de como seria o cotidiano com o meio ambiente seriamente comprometido.

Na cena 2, em que era abordada a poluição do ar, os espectadores ficaram surpresos com o fogo representando a queima das matas e a simulação da destruição da camada de ozônio.

A cena 3, referente a poluição da água, foi bastante dinâmica pois houve a participação direta do público, na qual três pessoas subiram no palco e participaram dos experimentos "água que muda de cor" e "água raivosa". A plateia interagiu bastante de forma divertida nas cenas 4 e 5 , principalmente na cena 5 que se tratava da reciclagem. Durante esta cena, foi utilizada a "Máquina da Reciclagem". Houve uma simulação demostrando que todo lixo jogado na máquina era transformado em objetos reciclados, como camiseta produzida a partir de garrafas PETs e carteiras feitas de caixa de leite. Os alunos expectadores foram incentivados a participar, jogando o lixo na máquina ao som da música“3 R's” do cantor americano Jack Johnson. 


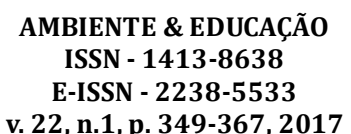

Para verificar a assimilação dos conceitos abordados do teatro pelos alunos, foram aplicados os questionários pré e pós apresentação e feito o tratamento dos dados. Esses questionários foram baseados na escala linkert, com escala variando de um a cinco.

Os dados obtidos no questionário pré apresentação, foram respondidos por cento e cinquenta estudantes e podem ser observados na figura 7:

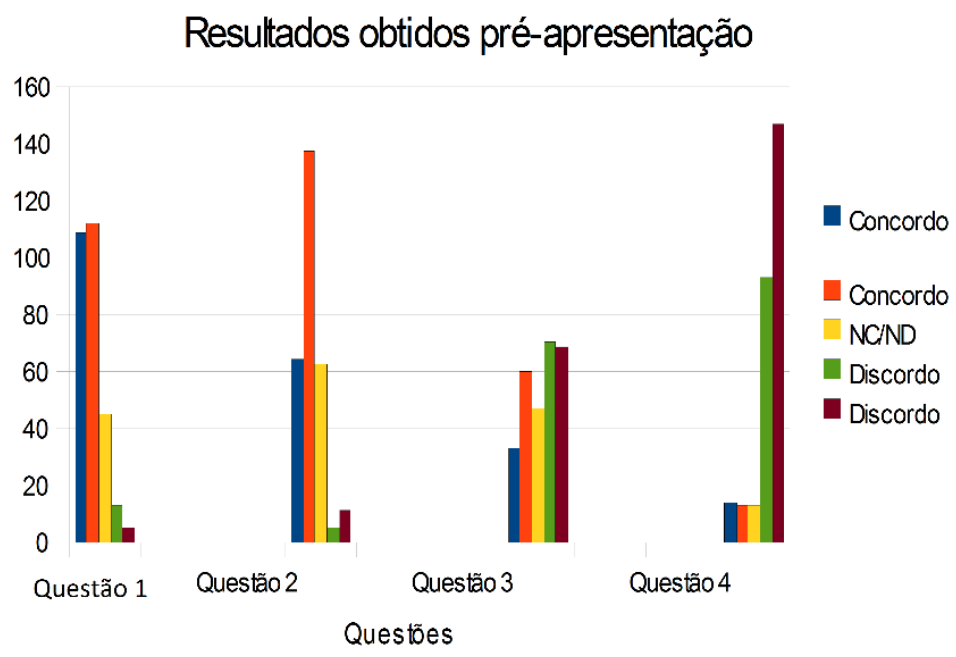

Figura 7: Gráfico com resultados pré apresentação.

De acordo com o gráfico apresentado na figura 7 , pode-se determinar que $70 \%$ das pessoas se mostraram bastante animadas para o início das apresentações (Questão 2) e que $82 \%$ acham que a aula de ciências pode ser divertida (Questão 4). Ainda de acordo com este gráfico é possível determinar que apenas cerca de 39\% dos espectadores acreditam ser plenamente responsáveis pelo meio ambiente (Questão 1) e 32\% achavam que as aulas de ciência eram desinteressantes e entediantes.

Resultados obtidos pós-apresentação

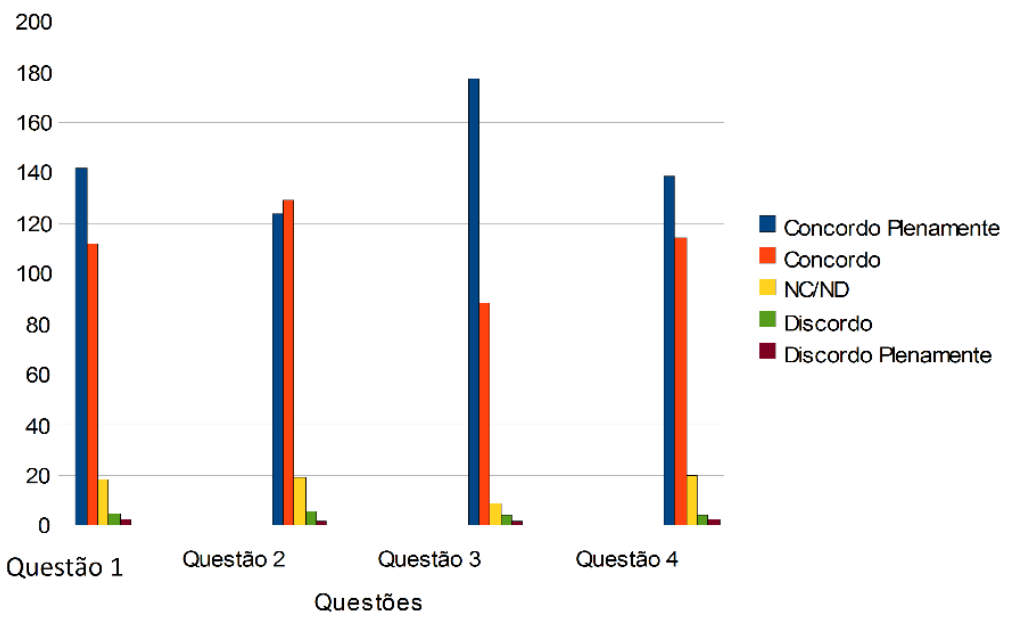

Figura 8: Gráfico com os resultados pós apresentação. 
De acordo com o gráfico (figura 8) é possível determinar que após a apresentação teatral (questionário respondido por 180 estudantes), houve um aumento considerado do público que se sentia plenamente responsável pela preservação do meio ambiente de $39 \%$ para 64\% (Questão 3). Aproximadamente, $89 \%$ do público considerou a apresentação divertida superando suas expectativas. Também houve um aumento do público que mudou de opinião sobre as aulas de ciências, se estas apresentadas de forma lúdica e com auxílio de experimentos, sendo esse público 91\% do total (Questão 4).

\section{CONCLUSÃO}

De acordo com os dados dos questionários, as apresentações tiveram caráter positivo, mostrando uma grande aceitação do público de $82 \%$. Isso comprova que a utilização do lúdico, com uma linguagem simples e próxima do dia a dia dos jovens, realmente surte efeito em sua formação. As apresentações também proporcionaram maior conhecimento e experiência com o trabalho em grupo e o relacionamento com o público para os alunos realizadores do projeto.

O que se pode observar com a pesquisa realizada é que a interação, que é a característica da aprendizagem significativa foi alcançada a partir do momento em que os alunos após expressarem suas opiniões prévias sobre responsabilidade ambiental se depararam com informações, pós apresentação, diferentes das que eles concebiam sobre as variáveis ambientais e a responsabilidade de cada um na preservação ambiental, evidenciado pela questão 3 .

\section{REFERÊNCIAS}

ARROIO, Agnaldo et al. O show da química: motivando o interesse científico. Química Nova, v. 29, n. 1, p. 173, 2006.

BRASIL. Política Nacional de Educação Ambiental - Lei no 9795/1999, Art 1º. Disponível em: <http://www.mma.gov.br/port/conama/legiabre.cfm?codlegi=321>. Acesso em: 30 de agosto de 2016.

CUNHA, Gabriela Lopes; SILVA, Liliane Faria da. Lúdico como recurso para o cuidado de enfermagem pediátrica na punção venosa. Northeast Network Nursing Journal, v. 13, n. 5, 2012. FETTER, S. I.; MÜLLER, J.; SILVA, M. C. Horta Escolar: Teoria e prática para uma vida saudável-Educação ambiental na Escola Estadual João Mosmann/Parobé/RS. Revista Brasileira de Agroecologia, [S.1.], v. 1, n. 1, 2006.

FORTUNA, Tânia Ramos. O jogo e a educação: uma experiência na formação do educador. SANTOS, SMP Brinquedoteca: a criança, o adulto e o lúdico. Petrópolis: Vozes, p. 73-85, 2000. 


$$
\begin{gathered}
\text { AMBIENTE \& EDUCAÇÃo } \\
\text { ISSN - 1413-8638 } \\
\text { E-ISSN - 2238-5533 } \\
\text { v. 22, n.1, p. 349-367, } 2017
\end{gathered}
$$

GIORDAN, Marcelo. O papel da experimentação no ensino de ciências. Química nova na escola, v. 10, n. 10, p. $43-49,1999$.

JACOBI, Pedro et al. Educação ambiental, cidadania e sustentabilidade. Cadernos de pesquisa, v. 118, n. 3, p. 189-205, 2003.

OLIVEIRA, Vitor Marinho de. O que é Educação Física. São Paulo: Brasiliense, 1985.

PASSOS, Calmon de; NOGUEIRA, Priscilla. A conferência de Estocolmo como ponto de partida para a proteção internacional do meio ambiente. Revista Direitos Fundamentais \& Democracia, v. 6, n. 6, 2009.

SANTOS, Ana Claudia Ventura dos. Teatro na sala de aula: abordagem inovadora no ensinoaprendizagem no processo de Educação Ambiental. AMBIENTE \& EDUCAÇÃO-Revista de Educação Ambiental, v. 19, n. 2, p. 51-65, 2016.

SILVEIRA, Alessandro Frederico da; ATAÍDE, Ana Raquel Pereira de; FREIRE, Morgana Farias. Atividades lúdicas no ensino de ciências: uma adaptação metodológica através do teatro para comunicar a ciência a todos. Educar em Revista, n. 34, 2009. 